\title{
In vivo determination of body composition by tritium dilution in the rat
}

\author{
BY NANCY J. ROTHWELL AND M. J. STOCK \\ Department of Physiology, Queen Elizabeth College, Kensington, \\ London $W 87 \mathrm{AH}$
}

(Received 7 November 1978 - Accepted 16 January 1979)

\begin{abstract}
Total body water was determined in vivo by tritium dilution in thirty-two male and female rats. Body water obtained by tritium dilution and body fat calculated from this value correlated significantly with body water and fat obtained by analysis ( $0.985,0.855$ respectively). There was no significant difference between values for fat assessed by the direct and indirect methods.
\end{abstract}

The measurement of body composition is of fundamental importance to many nutritional and physiological studies and has generally relied on direct carcass analysis. This technique however, is arduous, lengthy and requires the slaughtering of animals and, although several methods of determining body composition in vivo have been developed in man, few have been employed to any great extent in laboratory animals. Tritium dilution, for example, has been shown to produce a reliable estimate of body water in the rat (Foy \& Schnieden, I960) but no attempt has been made to use this technique to predict body fat content. The purpose of the present study was therefore to test the reliability of the tritium method for estimating body composition and carcass energy content in vivo in the rat.

\section{EXPERIMENTAL}

Sixteen male and sixteen female Sprague-Dawley rats weighing between 150 and $360 \mathrm{~g}$ were used in this study. These animals were maintained on a standard rat diet (Oxoid; Christopher Hill Group Ltd) and were fed normally until the morning of the experiment. At 09.00 hours all animals were injected with ditritium oxide ( $10 \mu \mathrm{Ci}$ in $\mathrm{I} \mathrm{ml}$ sterile saline ( $9 \mathrm{~g}$ sodium chloride/l) injected intraperitoneally) and, after a $2 \mathrm{~h}$ equilibration period, were killed by cervical dislocation. A rapid blood sample ( $1 \circ \mathrm{ml})$ was taken into a heparinized syringe by cardiac puncture, and then centrifuged. Three $100 \mu \mathrm{l}$ samples of plasma were taken and the tritium content of plasma was estimated by liquid scintillation counting in a Packard Tri-Carb counter using $10 \mathrm{ml}$ Instagel (Packard Instrument Ltd) as scintillant. The specific activity of plasma water was calculated using a value of $93.7 \%$ for the water content of plasma; this value was obtained from the literature and also verified experimentally. A sample of the injected dose of tritiated water was also counted in triplicate, and total body water calculated from the specific activity ratio, dose: plasma water. The rat carcasses were frozen at $-20^{\circ}$ for later determination of carcass composition.

\section{METHODS}

Preparation of carcasses. The frozen carcasses were chopped into small pieces (approximately $300 \mathrm{~mm}^{2}$ ) and then dried to constant weight in a vacuum oven at $80^{\circ}, 10.6 \mathrm{KN} / \mathrm{m}^{2}$. After drying, the whole carcass was ground and homogenized in a domestic mincer.

Fat analysis. Duplicate $5 \mathrm{~g}$ samples of dried homogenized carcass were extracted in $50 \mathrm{ml}$ chloroform-methanol $(\mathrm{I}: \mathrm{I}, \mathrm{V} / \mathrm{v} ; \mathrm{CM})$, for approximately $3 \mathrm{~h}$. The extraction mixture was filtered through phase-separating paper (Whatman PS), the filtrate being retained, and the carcass was re-extracted in $25 \mathrm{ml} \mathrm{CM}$ for a further $\mathrm{I} h$, after which it was also 
Table I. Comparison of body water $(\mathrm{ml})$ obtained by tritium dilution $(\mathrm{y})$ and carcass analysis $(\mathrm{x})$

(Mean values with their standard errors)

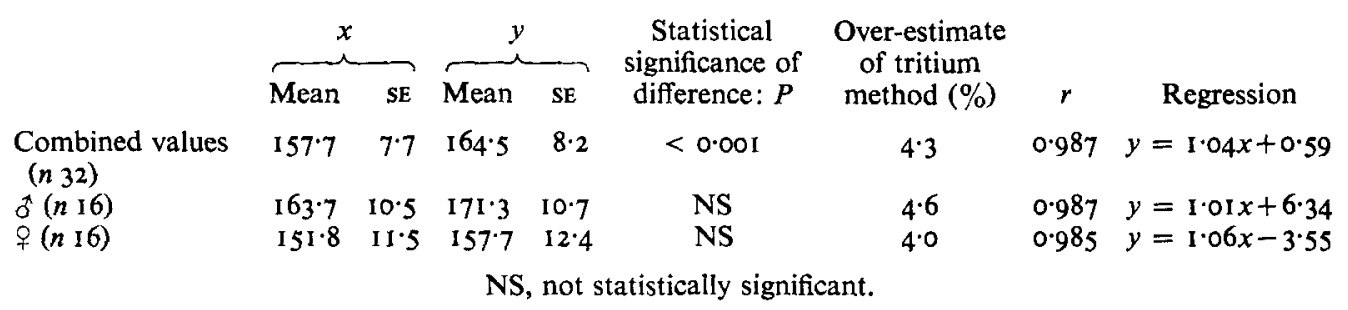

Table 2. Comparison of body fat $(\mathrm{g})$ obtained by tritium dilution $(\mathrm{y})$ and carcass analysis $(\mathrm{x})$

(Mean values with their standard errors)

\begin{tabular}{|c|c|c|c|c|c|c|c|}
\hline & \multicolumn{2}{|c|}{$x$} & \multicolumn{2}{|c|}{$y$} & \multirow{2}{*}{$\begin{array}{l}\text { Statistical } \\
\text { difference: } P\end{array}$} & \multirow[b]{2}{*}{$r$} & \multirow[b]{2}{*}{ Regression } \\
\hline & Mean & SE & Mean & SE & & & \\
\hline $\begin{array}{l}\text { Combined } \\
\left(n_{32}\right)\end{array}$ & $25 \cdot 74$ & $2 \cdot 6 I$ & $22 \cdot 58$ & $1 \cdot 65$ & NS & 0.855 & $y=0.532 x+8.861$ \\
\hline $0(n 16)$ & $27 \cdot 19$ & $4 \cdot 25$ & 23.87 & $2 \cdot 77$ & NS & 0.868 & $y=0.563 x+8.569$ \\
\hline$q(n 16)$ & $21 \cdot 30$ & $1 \cdot 82$ & $24 \cdot 25$ & $3 \cdot 12$ & NS & 0.835 & $y=0.471 x+9.960$ \\
\hline
\end{tabular}

filtered through PS paper. The two filtrates were combined, made up to $100 \mathrm{ml}$ with chloroform, and $20 \mathrm{ml}$ samples were dried to constant weight for gravimetric determination of fat.

Energy content. Duplicate I g samples of dry carcass were weighed into bomb crucibles, and the energy density was determined by ballistic bomb calorimetry (Miller \& Payne, 1959), using sucrose as the thermochemical standard.

Statistical analysis. All values given are means with their standard errors. Statistical differences were assessed using the Student's $t$ test for matched values, and correlations were obtained using the method of least squares. All probabilities given are two-tailed.

\section{RESULTS}

The mean value for total body water obtained by the tritium dilution method was approximately $4 \%$ greater than that obtained by dessication in both males and females (Table $\mathrm{I}$ ). Although these values differ significantly, the two methods correlate well $(r 0.987$, $P<0.0000 \mathrm{I}$ ), indicating that the over-estimate of the tritium dilution method is constant over the range of body-weights tested. Thus, body water determined by tritium dilution can be corrected for this over-estimate using the equations shown in Table $I$.

The water content of fat-free mass (W\% FFM) was determined from the analytical values for total body water and fat-free carcass, and was found to differ significantly between males $(73.07 \pm 0.26 \%)$ and females $(72.28 \pm 0.26 \%, P<0.05, n=16)$. Using these values, body fat content was calculated from the corrected values for body water determined by tritium dilution as follows:

$$
\text { Body fat }(\%)=\operatorname{Ioo}\left(1-\frac{\text { body water }(\%)}{W \% \text { FFM }}\right) \text {. }
$$

The mean value for body fat calculated in this way was not significantly different from 
that obtained by direct analysis (Table 2) and the two methods of estimating fat content were significantly correlated for males and females. The mean carcass energy content of all animals was $2040 \pm 1320 \mathrm{KJ}$ and a significant correlation was found to exist between carcass energy content and body fat estimated from the tritium dilution method using the previously-mentioned equation, $(r 0.83$; carcass energy $(\mathrm{kJ})=59.8$ body fat $(\mathrm{g})+420.2$; $P<0.0001, n 32)$.

\section{DISCUSSION}

The results of this study demonstrate that the tritium dilution method produces a reliable estimate of body water content in the rat. The over-estimate of this technique agrees with that reported by Elkinton \& Danowski (1955), and Foy \& Schnieden (1960) and is probably due to proton exchange between tritium and hydrogen other than that present in water. However, the error of the tritium method is constant over a wide range of body-weights and can therefore be corrected using the equations shown in Table I. Previous workers have often determined body fat content from body water by assuming that W\% FFM is constant at approximately $73.2 \%$. This value is obtained from the data of Pace \& Rathbun (1945) and represents a mean value abstracted from a number of reports in several species. However, Pace \& Rathbun (1945) report a considerable range of values $(69 \cdot 9-76.3 \%)$, which suggests that separate consideration of each species might be advantageous. The values for $\mathrm{W} \% \mathrm{FFM}$ obtained in this study are similar to those reported by other workers (Hatai, 1917; Light et al. 1934; Ashworth \& Cowgill, 1938; Mendez \& Kollias, 1977), but in all these papers values for both sexes were combined, whereas in the present study a significant difference between the W\%FFM of males and females was observed. The $\mathrm{W} \% \mathrm{FFM}$ was apparently unaffected by age or fat content since the correlation between W $\%$ FFM and body-weight or body fat showed a gradient of zero. Mendez \& Kollias (1977) have also shown that the composition of fat-free mass is largely unaffected by most dietary and experimental conditions. Body fat calculated from the tritium estimate of body water correlated well with the value obtained by direct analysis and mean values were not significantly different.

The tritium method of determining body composition offers several advantages over direct analysis. This technique can be carried out in vivo on conscious animals, and injection of tritium and subsequent blood sampling from the tail involves little trauma. This is particularly advantageous when serial measurements of body composition are required since direct measurements involve killing a sample of experimental animals selected, usually, on the basis of body-weight. This involves large numbers of animals and relies on the assumption that animals of the same body-weight have the same composition; a supposition which may not necessarily hold true for adult rats. In the present study, for example, no correlation was found to exist between body-weight and body energy content in rats over $250 \mathrm{~g}(r 0.49$, not significant, $n$ I6). The tritium method is rapid and allows a large number of determinations to be carried out daily, and therefore compares favourably with the arduous and time-consuming nature of direct analysis. Tritium can be assayed accurately by scintillation counting and is a relatively safe isotope which can be used in small doses. Some workers have used as much as $100 \mathrm{mCi}$ tritium/rat (Tisavipat et al. 1974), whereas in fact a dose of $10 \mu \mathrm{Ci}$ is sufficient to produce a minimum of I000 disintegrations/min per $100 \mu \mathrm{l}$ plasma in adult rats of up to $350 \mathrm{~g}$ body-weight.

The tritium dilution technique therefore offers a rapid and accurate method of estimating body composition in the rat during the course of an experiment, and thereby avoids the assumptions and expense of the comparative carcass technique.

The authors would like to thank Mrs G. S. Davies for her technical assistance. 


\section{REFERENCES}

Ashworth, U. S., \& Cowgill, G. R. (1938), J, Nutr. 15, 73.

Elkington, J. R., \& Danowski, T. S. (1955). The Body Fluids, p. 80. Baltimore Maryland: Williams \& Wilkins.

Foy, J. M. \& Schnieden, H. (1960). J. Physiol., Lond. 154, 169.

Hatai, S. (1917). Am. J. Anat. 21, 23.

Light, A. E., Smith, P. K., Smith, A. H. \& Anderson, W. E. (1934). J. biol. Chem. ro7, 689.

Mendez, J. \& Kollias, J. (1977). Am. J. Physiol. 42, 731.

Miller, D. S. \& Payne, P. R. (1959). Br. J. Nutr. 13, 319.

Pace, N. \& Rathbun, E. N. (1945). J. biol. Chem. 158, 689.

Tisavipat, A., Vibulsreth, S., Sheng, H. P., Huggins, R. A. (1974). J. appl. Physiol. 37, 699. 